\title{
Author Correction: Gut microbiota- mediated protection against influenza virus subtype H9N2 in chickens is associated with modulation of the innate responses
}

AlexanderYitbarek ${ }^{1}$, Khaled Taha-Abdelaziz ${ }^{1,2}{ }^{2}$ Douglas C. Hodgins ${ }^{1}$, Leah Read ${ }^{1}$, Éva Nagy ${ }^{1}$, J. Scott Weese ${ }^{1}$, Jeff L. Caswell ${ }^{1}$, John Parkinson ${ }^{3,4,5}$ \& Shayan Sharif ${ }^{1}$

Correction to: Scientific Reports https://doi.org/10.1038/s41598-018-31613-0, published online 04 September 2018

The original version of this Article omitted an affiliation for Khaled Taha-Abdelaziz. The correct affiliations for Khaled Taha-Abdelaziz are listed below:

Department of Pathobiology, Ontario Veterinary College, University of Guelph, Guelph, ON N1G 2W1, Canada.

Pathology Department, Faculty of Veterinary Medicine, Beni-Suef University, Al Shamlah, Beni-Suef, 62511, Egypt.

This has now been corrected in the HTML and PDF versions of this Article.

(a) Open Access This article is licensed under a Creative Commons Attribution 4.0 International C. License, which permits use, sharing, adaptation, distribution and reproduction in any medium or format, as long as you give appropriate credit to the original author(s) and the source, provide a link to the Creative Commons license, and indicate if changes were made. The images or other third party material in this article are included in the article's Creative Commons license, unless indicated otherwise in a credit line to the material. If material is not included in the article's Creative Commons license and your intended use is not permitted by statutory regulation or exceeds the permitted use, you will need to obtain permission directly from the copyright holder. To view a copy of this license, visit http://creativecommons.org/licenses/by/4.0/.

(c) The Author(s) 2018

\footnotetext{
${ }^{1}$ Department of Pathobiology, Ontario Veterinary College, University of Guelph, Ontario, N1G 2W, Canada. ${ }^{2}$ Pathology Department, Faculty of Veterinary Medicine, Beni-Suef University, Al Shamlah, 62511, Beni-Suef, Egypt. ${ }^{3}$ Department of Computer Science, University of Toronto, Toronto, M5S 3G4, Canada. ${ }^{4}$ Division of Molecular Structure and Function, Research Institute, Hospital for Sick Children, Toronto, Ontario, M5G 1X8, Canada. ${ }^{5}$ Departments of Biochemistry and Molecular Genetics, University of Toronto, M5S 1A8, Toronto, Canada. Correspondence and requests for materials should be addressed to S.S. (email: shayan@uoguelph.ca)
} 